\title{
OMBROPHYTON SUBTERRANEUM, NUEVA ESPECIE HOLOPARÁSITA REGISTRADA EN LA FLORA DESERTICA DE TACNA
}

Responsable: Rosario Zegarra Zegarra

\begin{abstract}
RESUMEN
En este corto articulo se reporta la existencia de una nueva e interesante especie vegetal en los ecosistemas áridos y semiáridos de las zonas altoandinas de Tacna (a $2800 \mathrm{msnm}$ ). Esta especie fanerogámica Ombrophyton subterraneum, Balanophoraceae pertenece a un grupo de plantas parásitas que habitan en subsuelos cuyos haustorios parasitan a raices de otras especies fanerógamas, tales como Baccharis salicifolia.
\end{abstract}

\begin{abstract}
It is reported in this short communication paper the occurrence of a new interesting plant species in the dry and semiarid ecosystem of the highlands of Tacna (at 2800 masl). This phanerogamic species Ombrophyton subterroneum, Balanophoraceae belongs to a group of underground plants which haustorius parasite the roots of others flowering species such as Baccharis salicifolia.
\end{abstract}

\section{INTRODUCCIÓN}

En las angiospermas se encuentran organismos especializados respecto a la nutrición, los cuales han pasado a ser parcialmente heterótrofos $y$, en raros casos, incluso llegan a serlo por completo. Una parte de ellos se han especializado en vivir a expensas de otros vegetales y toman de ellos el alimento por medio de haustorios que se ponen en estrecho contacto anatómico sobre todo con el sistema conductor del hospedante. Mientras que las plantas hemiparásitas se limitan a conectar sus sistemas de conducción de agua con el de la planta parasitada, se distinguen poco, en muchos casos, de los vegetales afines completamente autótrofos, tomando coloraciones más pálidas verde amarillentas. Sin embargo, las plantas holoparásitas obligatorias, que se reconocen de inmediato por la carencia casi absoluta de clorofila, presentan a menudo una o más reducción de los órganos vegetativos. Con la disminución de la clorofila, en las plantas parásitas, las hojas pasan a ser innecesarias y se reducen a escamas amarillentas, poco aparentes o desaparecen por completo. Incluso los tallos están a menudo más o menos simplificados y no presentan pigmento verde o lo tienen muy pálido. Como consecuencia de ello la reducción del follaje; disminuye también la transpiración y las raices desaparecen tambièn en muchos casos. El xilema de los haces conductores alcanza, asimismo, escaso desarrollo y la formación de leño se da solo con pequeña intensidad. La pérdida de los dispositivos asimiladores ha conducido empero a la formación de nuevos caracteres estructurales, al desarrollo de órganos en suctores particulares que son los haustorios, los cuales permiten a los parásitos penetrar al cuerpo del hospedante, hasta las vías conductoras del mismo, y utilizar el contenido de ellas para la nutrición.

En este sentido, dentro de las plantas superiores Famerigamos se distinguen dos grupos de plantas parásitas:

Los HEMIPARÁSITOS: Uno de ellos es Ligaria cuneifolia muy conocido como el "Kintral" "Liga", la cual destaca por su follaje verde y por sus flores rojizas muy vistosas. Crece sobre plantas de manzano, peral, duraznero y otras especies silvestres como el molle en las vertientes occidentales semiáridas de Tacna.

Los HOLOPARÁSITOS: Se tienen a las especies Orobanche tacnaensis y a Ombrophyton subterraneum caracterizadas por la presencia de haustorios que son verdaderos órganos chupadores mediante los cuales se conecta con los tejidos conductores del hospedante que son en general especies de la familia Asteráceas: Tessatia o integrifolia y Baccharis salicifolia. Las especies de los géneros Cuscuta, Quinchamalium también pertenecen a este grupo de plantas holoparásitas y se presentan esporádicamente en la vegetación desértica de las lomas de Sama-Locumba.

\section{MATERIALYMÉTODOS}

Especimenes de Ombrophyton subrraneum de la familia Balanophoraceae fueron colectados en las vertientes accidentales semiáridos del departamento de Tacna, cerca de Tarata. El material colectado fue analizado en sus caracteres fenotipicos y luego identificado taxonómicamente como 0. subterraneum posteriormente, la ubicación taxonómica de este espécimen fue confirmada por la profesora de Botánica Dra. Nilda Vignale de la Universidad de Jujuy, Argentina.

Observaciones Generales Generales y Descripción de Ombrophyton Suberraneum (Asplend)

En general, esta especie se caracteriza por ser una hierba o planta parásita subterránea, carnosa y suculenta, sin clorofila, rojiza púrpura, creciendo sobre raices de plantas leñosas como Baccharis salicifolia "Chare" con un sistema caulinar extenso subterráneo formado por un tubérculo farináceo conectado a la raiz hospedante a partir del cual se extienden estructuras rizomatosas en varias direcciones; el rizoma es lobulado, filiforme o cilindrico. Las hojas son escuamiformes o están ausentes y ligeramente pigmentadas de rojo claro.La inflorescencia es crasa con numerosas flores reunidas en espigas 0 paniculas gruesas claviformes 0 
globosas ensiformes.Las flores son unisexuales pequeñas epiginas $\sin$ perianto 0 con 28 pétalos libres 0 unidos en un tubo. Estambres 28 libres o unidos en un tubo o columna central. Anteras 12 tecadas, introrsas o extrosas, libres 0 unidas en un sinandro. Dehiscencia longitudinal o poricida. (Fig. $N^{\circ} 01$ y Fig. N 02).Ovario ínfero, sólido. Óvulos 12 estilos (0) 13 estigmas simples. Fruto carnoso o seco generalmente con una semilla. Crece en suelos áridos arenosos 0 en suelos de textura arcillo-arenosos.Puede propagarse sexualmente. El tubérculo se consume por la presencia de carbohidratos, minerales y proteinas.

\section{DISCUSIÓNYCONCLUSIONES}

En el Perú la especie parásita Ombrophyton subrraneum se ha registrado para la selva peruana (Brako \& Zarucchi, 1993), también se señala para alturas de 35004000 msnm. (Vignale N.N., 2006) en los Andes de Bolivia y Argentina y es conocida como "Ancañoca". Es la primera vez que se registra dentro de la vegetación y flora desértica y semiárida del departamento de Tacna. Esta planta es considerada en regiones como Parinacota (Chile) como planta alimenticia y medicinal. Mayormente parasita a las raices de la planta "Chare" Baccharis salicifolia y de la tola "Parastrephia lepidophylla".

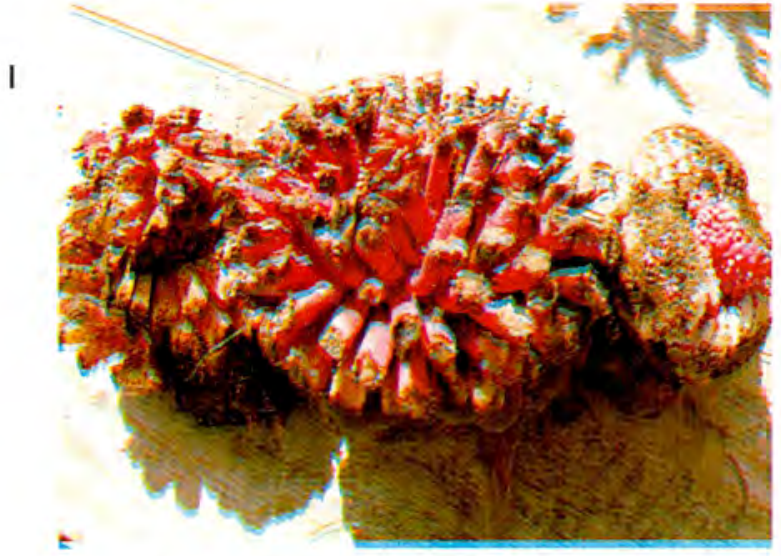

Figura $N^{\circ}$ 01: Espécimen de Ombrophyton subrraneum colectado cerca de Tarata, Tacna, mostrando flores tubulares rojizas.

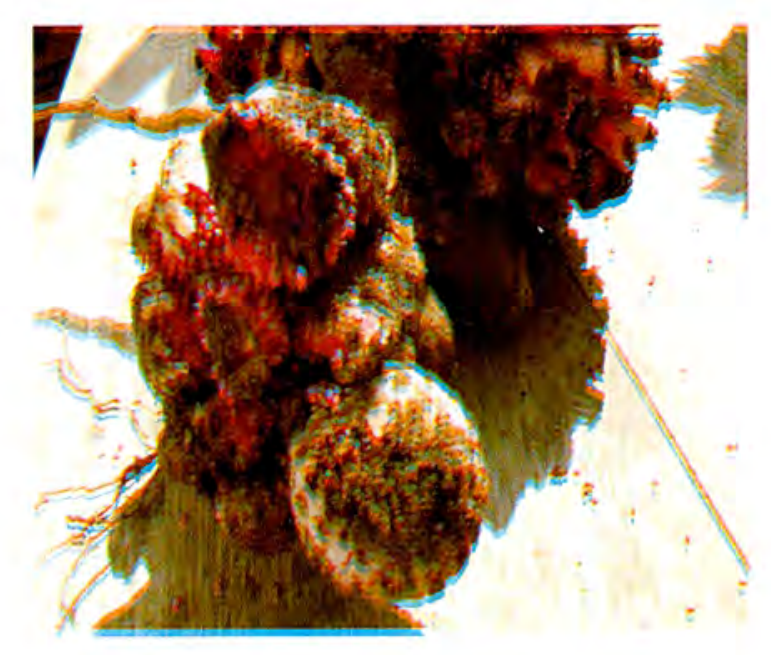

Figura $\mathbf{N}^{\circ}$ 02: Planta de Ombrophyton subrraneum mostrando flores muy desarrolladas y rudimentos o yemas florales.

\section{BIBLIOGRAFÍA}

Brako Lois and Zarucchi, James L (1993), Catálogo de las Angiospermas y Gimnospermas del Perú. Missouri Botanical Garden.

Soliz Valdez Víctor Hugo (2002), Estudios etnobotánicos de Ombrophyton subrraneum Aspl. Hansen (Ancañoca) en tres áreas de la provincia Nor Lipez del departamento de Potosí. Universidad Autónoma Tomas Frías.

Vignale, N. D. (1997), LasAncañocas en la biodiversidad de la puna. Nuestra tierra 2: 4 5. Argentina. 